Scientific Research \& Studies Center-Faculty of Science- Zagarig

University- Egypt

Biochemistry Letters

Journal home page:

\title{
Correlation between oxidative stress and Hydroxyproline content in Liver Fibrosis
}

\begin{abstract}
Ahmed Nabil ${ }^{1}$, Islam S. Ali ${ }^{2}$, Gamal Shiha ${ }^{3}$, Faten Zahran ${ }^{4}$
1 Biotechnology and Life Sciences Department, Faculty of Postgraduate Studies for Advanced Sciences, Beni-Suef University, Egypt.

${ }^{2}$ Delta University for Science and Technology, Gamasa, Dakahlia, Egypt

${ }^{3}$ Hepatology and Gas troenterology Unit, Internal Medicine Department, Faculty of Medicine, Mans oura Uni versity, Mansoura, Egypt.

${ }^{4}$ Chemis try Department, Faculty of Science, Zagazig University, Zagazig, Egypt

ARTIC LE INFO

Article history:

Received:

Accepted : 16/3/2021

Available online :

Keywords:

Hepatic fibrosis

Nilotinib

A B S TR A C T

Background \& Objectives: Hepatic fibrosis is the extreme extracellular matrix buildup of collagen due to the chronic liver disorders. Progressive liver fibrosis results in cirrhosis and hepatic failure. Nilotinib is considered a $2^{\text {nd }}$ generation tyrosine kinase inhibitor, which exhibited antifibrotic efficacy. Stem cells release cytokines and growth factors which exhibited paracrine-mediated antifibrotic and anti-inflammatory effects in vitro and in vivo. Hence, stem cells conditioned medium (SC-CM) may have an antifibrotic role. This study is designed to explain the association between the oxidative stress markers and the hydroxyproline content in liver fibrosis. Methods: Sixty male wistar rats were distributed into six major groups; control group, $\mathrm{CCl}_{4}$ group, Free conditioned media group, $\left(\mathrm{CCl}_{4} \&\right.$ Nilotinib) group, $\left(\mathrm{CCl}_{4} \&\right.$ stem cells exosomes $)$ group, and $\left(\mathrm{CCl}_{4} \&\right.$ Nilotinib \& stem cells exosomes $)$ group. They had an intraperitoneal injection with $\mathrm{CCl}_{4}$ for nine weeks and had treatments of Nilotinib, stem cell exosomes (extracted from Liver mesenchymal stem cells), and a combined treatment of Nilotinib and stem cell exosomes from the $5^{\text {th }}$ week to the $9^{\text {th }}$ week of $\mathrm{CCl}_{4}$ intoxication. Oxidative stress parameters (e.g. MDA, SOD, GSH, CAT, NO, and NOS) and hydroxyproline content were estimated for each group. Results: results showed a significant positive correlation between Hydroxyproline and MDA, NO and NOS. Also, there is a significant negative correlation between Hydroxyproline and GSH, SOD and CAT. Conclusion: There is a signific ant positive correlation between Hydroxyproline and MDA, NO and NOS. And there is a significant negative correlation between Hydroxyproline and GSH, SOD, CAT.
\end{abstract}

(c) Publisher All rights reserved 2021.
Fibrosis is a prevalent pathological progression for the most of liver disorders

Corresponding author: Islam S. Ali

Basic Sciences Department, Faculty of Oral and Dental Medicine, Delta University for Science and Technology, Gamasa,

Dakahlia, Egypt..E-mail: islamsameh_89@yahoo.com 
that results in hepatic cirrhosis and hepatocellular carcinoma (HCC). It results from nearly all chronic liver disorders mainly rising from metabolic, viral, autoimmune disorders [1]. Fibrosis is a consequence of chronic wound healing and is described as the advanced replacement of efficient liver tissue with extracellular matrix which is rich with collagen I and III; it disturbs the normal construction and functions of the liver particularly in the late stage of liver cirrhosis. Liver fibrosis is also believed a precancerous condition which supplies microenvironments where 1ry tumors may progress [2].

Oxygen free radicals act as a significant part in tissue destruction in many liver diseases. Free radicals like the hydroxyl radicals and superoxide, can give rise to a destruction in cellular constituents by peroxidation of lipoproteins and nucleic acids [3]. Peroxidation is initiated by free radicals which leads to oxidative destruction of polyunsaturated fatty acids of cell membranes and also leads to making aldehyde metabolites such as malondialdehyde (MDA) [4].

Another study reported that (Nitric oxide) NO plays a role in liver fibrosis. NO activates guanylyl cyclase (GC) by connecting to its metal center. This forms cyclic guanosine monophosphate (cGMP) that connects to cGMP-dependent protein kinases (PKGs) and enable several biological processes like platelet aggregation, vasodilation and neurotransmission. Inducible nitric oxide synthase (iNOS)-derived NO is implicated in the growth and maintenance of many liver diseases [5]. Also there is a study reported that the actions of superoxide dismutase (SOD), Catalase (CAT) were found to be lower in cirrhotic liver in comparison with healthy liver. Those changes were related to a reduction of reduced glutathione (GSH) levels in cirrhotic liver tissue in comparison with healthy liver tissue [6]. Furthermore, it was reported that the apoptosis of hepatocytes causes the induction of the inflammatory cells to the injured liver and discharge of profibrogenic cytokines such as TGF- $\beta 1$. TGF- $\beta 1$ is crucial to activating the fibrogenic myofibroblasts, which release extracellular matrix proteins like collagen Type I and hydroxyproline [7].

The present study is designed to explain the correlation between oxidative stress and hydroxyproline in the advancement of liver fibrosis.

\section{Material and Methods: \\ Expe rimental Animals :}

Fifty male Wistar rats (180-200 gm) were purchased from the Egyptian Organization for Biological Products and Vaccines (VACSERA, Giza, Egypt). The rats were housed at $21 \pm 2^{\circ} \mathrm{C}, 50 \pm 5 \%$ relative humidity. Rats were preserved in cages at a steady environment and nutritional condition during the experiment. All the procedures associated with animal care, handling, treatment and scarification are firmly followed to the Guide for the Care and Use of Laboratory Animals published by the US National Institute of Health (Publication No.85-23, revised 1996).

\section{Study Design:}

Rats were distributed into six main groups (10 rats in each cage) as follows. Group 1: rats were injected with $1 \mathrm{ml} / \mathrm{kg}$ of corn oil for nine weeks. Group 2: rats had intraperitoneal injection of $1 \mathrm{ml} / \mathrm{kg}$ of $\mathrm{CCl} 4$ solution for nine weeks [8]. Group 3: rats were injected with $1 \mathrm{ml} / \mathrm{kg}$ of $\mathrm{CCl} 4$ solution intrperitoneally+ exosome free media ( $1 \mathrm{ml}$ daily) from the 5 th week to the 9th week of $\mathrm{CCl} 4$ intoxication. Group 4: rats had an intraperitoneal injection with 1 $\mathrm{ml} / \mathrm{kg}$ of $\mathrm{CCl}_{4}$ solution+ Nilotinib (20 $\mathrm{mg} / \mathrm{kg}$ daily) (formerly AMN107; Tasigna $\left.{ }^{\circledR}\right)$ from the $5^{\text {th }}$ week to the $9^{\text {th }}$ week of $\mathrm{CCl}_{4}$ intoxication [9]. Group 5: rats were injected with $1 \mathrm{ml} / \mathrm{kg}$ of $\mathrm{CCl}_{4}$ solution intraperitoneally $+1 \mathrm{ml}$ of stem cell exosomes/rat daily (From liver mesenchymal stem cells (10000 cells $\left./ \mathrm{cm}^{2}\right)$ ) from the $5^{\text {th }}$ week to the $9^{\text {th }}$ week of $\mathrm{CCl}_{4}$ intoxication [10]. Group 6: 
rats were injected with $1 \mathrm{ml} / \mathrm{kg}$ of $\mathrm{CCl}_{4}$ solution intraperitoneally+ stem cell exosomes (1 $\mathrm{ml}$ daily) + Nilotinib (20 $\mathrm{mg} / \mathrm{kg}$ daily) from the $5^{\text {th }}$ week to the $9^{\text {th }}$ week of $\mathrm{CCl}_{4}$ intoxication.

\section{Biochemical assays:}

Rats from the six groups were sacrificed and a general anesthesia called thiopental were used before the sacrification. A laparotomy and hepatectomy were done. The liver samples were kept in liquid nitrogen. GSH, NO, NOS, CAT, MDA, SOD and hydroxyproline were assessed by using BioVision reagent kits, USA. The tests were done according to the kit instructions [11] [12][13][14][15][16].

\section{Statis tical analysis :}

The Statistical Package for the Social Sciences (IBM SPSS, version 20) was applied for this study to analyze the statistics of the results. One-way ANOVA was made and the numbers were obtained as mean $\pm \mathrm{SD}$. A simple linear correlation was analyzed by Pearson's method for measuring the degree of dependency between variables (IBM SPSS).

\section{Results :}

\section{Oxidative stress markers among the studied groups:}

The administration of $\mathrm{CCl}_{4}$ gave rise to a significant elevation of NO, MDA and NOS in comparison with Group 1. Nilotinib and stem cells exosomes treatments significantly reduced the NOS and NO in comparison with Group 2. Stem cells exosomes treatment faintly reduced the elevated levels of MDA in comparison with Group 2, but the Nilotinib treatment gave rise to a significant reduction on MDA in comparison with Group 2. The combined treatment of Nilotinib and stem cells exosomes displayed a further significant decrease in NO, MDA and NOS than the other treatments. This study also showed no significance in NO, MDA and NOS between Group 2 and Group 3. The $\mathrm{CCl} 4$ administration gave rise to a significant reduction in hepatic CAT, GSH and SOD in comparison with Group 1.
Nilotinib and stem cells exosomes treatments significantly raised the SOD and GSH in comparison with Group 1. Stem cells exosomes treatment faintly raised the levels of CAT in comparison with Group 1, but the Nilotinib treatment gave rise to a significant elevation on CAT in comparison with Group 2. The combined treatment of Nilotinib and stem cells exosomes revealed a further significant increase in CAT, GSH and SOD than the other treatments. There was no significance in CAT, GSH and SOD between Group 1 and Group 2 (Table 1). Hydroxyprotine content among the studied groups

The administration of $\mathrm{CCl}_{4}$ gave rise to a significant elevation of Hydroxyproline in comparison with Group 1. Nilotinib treatment significantly reduced the Hydroxyproline content in comparison with Group 2, but the stem cells exosomes treatment faintly reduced the Hydroxyproline content in comparison with Group 2. The combined treatment of Nilotinib and stem cells exosomes displayed a further significant reduction in the Hydroxyproline content than the other treatments. This study also showed no significance in the levels of hydroxyproline content between Group 2 and Group 3 (Table 1).

\section{Correlation between Hydroxyproline content and all markers :}

There is a significant positive correlation between Hydroxyproline and MDA, NO and NOS. And there is a significant negative correlation between Hydroxyproline and GSH, SOD, CAT (Figure 1) (Table 2).

\section{Discussion:}

This present study revealed that combined treatment of Nilotinib and stem cells exosomes had a significantly greater antifibrotic outcome than each treatment alone. There were significant declines of hydroxylproline content and oxidative stress in the combined treatment group 
(Group 6) in comparison with each treatment alone.

The antifibrotic effect of combined treatment of nilotinib and stem cells exosomes may be owing to a synergic effect of the 2 types of treatment: Stem cells exosomes have anti-inflammatory impact and decrease injuries to hepatocytes that inhibit the hepatic stellate cells (HSCs) activation which results in HSCs apoptosis and fibrinolysis stimulation [17]. Otherwise, MSCs alter the macrophages' polarity to an antiinflammatory phenotype, elevate the making of matrix metalloproteinases for reducing the ECM, and increasing the phagocytosis of hepatocyte remains (throughout this process, macrophages elevate the pro-regenerative factors) [18]. Also, Nilotinib has antifibrotic effect through 3 main ways tangled in fibrogenesis: deactivation of $\mathrm{c}-\mathrm{Abl}$ tyrosine kinase which prompt TGF- $\beta$ leading to fibrogenesis, suppression of discoidin domain receptors and collagen receptors [9], thus MSCs exosomes cause fibrinolysis and Nilotinib causes fibrinogenesis.

This study showed a significant positive correlation between Hydroxyproline and MDA, NO and NOS. Also, there is a significant negative correlation between Hydroxyproline and GSH, SOD and CAT. Gabr et. al, reported that hydroxyproline is about $1 / 3$ of the amino acids in the collagen. Fibrosis activation depend mostly on the collagen fibers deposition. It is associated with over deposition of ECM, because of inequality between synthesis and degradation of ECM in hepatic tissues [19]. NOS produces $\mathrm{NO}$ from L-arginine in a reaction which converts arginine and oxygen into citrulline and NO, which in turn NO is capable of adjusting the matrix metalloproteinases' activity and the formation of constituents of ECM like the hydroxyproline [20] [21][22][23] and that's why there is a positive correlation between hydroxyproline and NO (or NOS).

Also, there is a studies reported that GSH plays an important role in detoxification within cells, mostly cells of the intestines, kidney, lungs and liver. GSH has a significant relationship with lipid peroxidation due to the ability of these molecules to combine with free radicals that start lipid peroxidation and reduced hydrogen peroxide formed inside cells. Lipid peroxidation is initiated by free radicals which leads to oxidative damage of polyunsaturated fatty acids which are constituent of cell membranes and also results in the production of reactive aldehyde compounds such as MDA [4][24]. And that's the reason for positive correlation between hydroxyproline and MDA and a negative correlation between hydroxyproline and GSH.

Also Arya et. al., reported that SOD is one of the key enzymes which defend the body against oxidative stress. This enzyme catalyzes conversion of $2 \mathrm{O}_{2}^{-}$to $\mathrm{H}_{2} \mathrm{O}_{2}$ and $\mathrm{O}_{2} \cdot \mathrm{H}_{2} \mathrm{O}_{2}$ can be changed into $\mathrm{O}_{2}$ and $\mathrm{H}_{2} \mathrm{O}$ by CAT [25]. Shin et al., reported that CAT participates in the protection of mitochondria against exogenous or endogenous $\mathrm{H}_{2} \mathrm{O}_{2}$ which causes lipid peroxidation for the hepatocytes [26]. And that's why there is a negative correlation between hydroxylproline and CAT (or SOD).

\section{Conclusion:}

Combined treatment of Nioltinib and stem cells exosomes was more antifibrotic than each treatment alone. Also, Oxidative stress markers were associated with the hydroxyproline content in liver fibrosis because there is a significant positive correlation between Hydroxyproline and MDA, NO and NOS. Also, there is a significant negative correlation between Hydroxyproline and GSH, SOD and CAT. 
References:

[1] Ellis EL, Mann DA. Clinical evidence for the regression of liver fibrosis, Review, Journal of Hepatology. 2012; vol. 56 j 1171-1180.

[2] Muddu AK, Guha IN, Elsharkawy AM, Mann DA. Resolving fibrosis in the diseased liver: translating the scientific promise to the clinic. Int $\mathrm{J}$ Biochem Cell Biol 2007;39:695-714

[3] Salaspuno M. Epidemiological aspects of alcoholic liver disease, ethanol metabolism, and pathogenesis of alcoholic liver injury, 1999; s. 1157-1178, In: J., Benhamou J.R., Mc Intery, N., Rizzetto, M., Rodes, J., eds. Oxford Textbook of Clinical Hepatology. Bircher, Oxford University Press, New York.

[4] Aksoy H, Koruk M, Akçay F. The Relationship Between Serum Malondialdehyde and Ceruloplasmin in Chronic Liver Disease. Turk J Biochem, 2003; 28(2):32-34.

[5] Iwakiri Y. Nitric oxide in liver fibrosis: The role of inducible nitric oxide synthase. Clin Mol Hepatol., 2015; 21(4):319-25.

[6] Czeczot H, Scibior D, Skrzycki M, Podsiad M. [Activity of antioxidant enzymes in patients with liver cirrhosis]. Wiad Lek., 2006; 59(11-12):762-6. [7]

Meng F, Wang K, Aoyama T, Grivennikov SI, Paik Y, Scholten D, Cong M, Iwaisako K, Liu X, Zhang M, Österreicher CH, Stickel F, Ley K, Brenner DA, Kisseleva T. Interleukin-17 signaling in inflammatory, Kupffer cells, and hepatic stellate cells exacerbates liver fibrosis in mice. Gastroenterology., 2012; 143(3):765-776.e3.

[8] Dong S, Chen QL, Song YN, Sun Y, Wei B, Li XY, Hu YY, Liu P, Su SB. Mechanisms of CCl4- induced liver fibrosis with combined transcriptomic and proteomic analysis. J Toxicol Sci., 2016; 41(4):561- 72.

[9] Shaker ME, Zalata KR, Mehal WZ, Shiha GE, Ibrahim TM. Comparison of imatinib, Nilotinib and silymarin in the treatment of carbon tetrachloride-induced hepatic oxidative stress, injury and fibrosis. Toxicol Appl Pharmacol., 2011; 252(2):165-75.

[10] Abd El Zaher F, El Shawarby A, Hammouda G, Bahaa N. Role of Mesenchymal Stem Cells Versus their Conditioned Medium on CisplatinInduced Acute Kidney Injury in Albino Rat. A Histological and Immunohistochemical Study. The Egyptian Journal of Histology, 2017; 40(1): 37-51.

[11] Ge rard-Monnier D, Erdelmeier I, Regnard K, Moze-Henry N, Yadan JC, Chaudiere J. Reactions of 1methyl-2phenylindole with malondialdehyde and 4hydroxyalkenals: Analytical applications to a colorimetric assay of lipid peroxidation. Chem. Res. Toxicol., 1998; 11:1176-1183.

[12] Miranda KM, Espey MG, Wink DA. A rapid, simple spectrophotometric method for simultaneous detection of nitrate and nitrite. Nitric Oxide., 2001; 5:62-71.

[13] Katerji M, Filippova M, DuerksenHughes P. Appoarches and methods to measure oxidative stress in clinical samples: Research applications in the cancer field. Eur. Oxid Med Cell Longev, 2019; 2019:1279250.

[14] Hadwan MH. Simple spectrophotometric assay for measuring catalase activity in biological tissues. BMC Biochem, 2018; 19(1);7.

[15] Farrokhfall K, Hashtroudi MS, Ghasemi A, Mehrani H. Comparison of inducible nitric oxide synthase activity in pancreatic islets of young and aged rats. Iran $\mathrm{J}$ Basic Med Sci., 2015; 18(2):115-21.

[16] Smith IK, Vierheller TL, Thorne CA. Assay of glutathione reductase in 
crude tissue homogenates using 5,5'dithiobis(2-nitrobenzoic acid). Anal Biochem., 1988; 175(2):408-13.

[17] Tsuchiya A, Takeuchi S, Watanabe T, Yoshida T, Nojiri S, Ogawa $\mathbf{M}$ and Terai S. Mesenchymal stem cell therapies for liver cirrhosis: MSCs as "conducting cells" for improvement of liver fibrosis and regeneration. Inflammation and Regeneration (2019) 39:18.

[18] Watanabe Y, Tsuchiya A, Seino S, Kawata Y, Kojimi Y, Ikarashi S, Starkey Lewis PJ, Lu WY, Kikuta H, Yamagiwa S, Forbes SJ, Ishii M, Tera S. Mesenchymal stem cells and induced bone marrow-derived macrophages synergistically improve liver fibrosis in mice. Stem Cells Transl Med. 2019;8:27184.

[19] Gabr SA, Alghadir AH, She rif YE, Ghfar AA. Hydroxyproline as a Biomarker in Liver Disease. Biomarkers in Liver Disease, 2016; 1-21. doi:10.1007/978-94-007-7742-2_26-1

[20] Forslund T. and Sundqvist T. Nitric oxide reduces hydrogen peroxide production from human polymorphonuclear neutrophils. Eur. J. Clin. Invest., 1992; 25, 9-14

[21] Trachtman H., Futte rweit S. and Singhal P. Nitric oxide modulates the synthesis of extracellular matrix proteins in cultured rat mesangial cells. Biochem. Biophys. Res. Commun., 1995; 207, 120 125.
[22] Kolpakov V., Gordon D. and Kulik T. J. Nitric oxide-generating compounds inhibit total protein and collagen synthesis in cultured vascular smooth muscle cells. Circ. Res., 1995; 76, 305-309.

[23] Moncada S., Palmer R. M. J. and Higgs E. A. Nitric oxide: physiology, pathophysiology, and pharmacology. Pharmacol. Rev., 1991; 43, 109-142

[24] Galicia-Moreno M, RosiqueOramas D, Medina-Avila Z, Álvare zTorres T, Falcón D, Higuera-de la Tijera F, Béjar YL, Cordero-Pérez P, Muñoz-Espinosa $L$, Pérez-Hernández JL, Kershenobich D, Gutierrez-Reyes G.

Behavior of OxidativeStress Markers in Al coholic Liver Cirrhosis Patients. Oxid Med Cell Longev, 2016; 2016:9370565.

[25] Arya A, Azarmehr N, Mansourian $\mathbf{M}$, Doustimotlagh AH. Inactivation of the superoxide dismutase by malondialdehyde in the nonalcoholic fatty liver disease: a combined molecular docking approach to clinical studies. Archives of Physiology and Biochemistry, 2019; 1-8. doi:10.1080/13813455.2019.1659827

[26] Shin SK, Cho HW, Song SE, Song DK. Catalase and nonalcoholic fatty liver disease. Pflugers Arch., 2018; 470(12):1721-1737. 
Table 1: Oxidative stress markers and hydroxyprotine content among the studied groups:

\begin{tabular}{|c|c|c|c|c|c|c|c|}
\hline Groups & $\begin{array}{l}\text { Hydroxyproline } \\
\text { content } \\
\text { (measure of } \\
\text { fibrosis) (ug/mg } \\
\text { liver } \\
\end{array}$ & $\begin{array}{l}\text { Malonaldehyde } \\
\text { (mmol / g } \\
\text { tissue ) }\end{array}$ & $\begin{array}{l}\text { Nitric oxide } \\
\text { (micro mol } \\
\text { /g tissue) }\end{array}$ & $\begin{array}{l}\text { Glutathione } \\
\text { reduced } \\
\text { (micromol/g } \\
\text { protein) }\end{array}$ & $\begin{array}{c}\text { Super } \\
\text { oxide } \\
\text { dismutase } \\
\text { (U/mg } \\
\text { protein) }\end{array}$ & $\begin{array}{c}\text { Nitric oxide } \\
\text { synthase } \\
(P \\
\text { MOL/MIN/mg } \\
\text { protein) }\end{array}$ & $\begin{array}{c}\text { Catalase } \\
\text { (mol / } \\
\text { min / gm } \\
\text { ) }\end{array}$ \\
\hline Control & $31.21 \pm 3.76$ & $77.93 \pm 5.88$ & $150.84 \pm 19.25$ & $23.47 \pm 3.56$ & $21.09 \pm 2.86$ & $18.03 \pm 2.61$ & $1.05 \pm 0.11$ \\
\hline $\mathrm{CCl} 4$ & $61.60 \pm 21.56$ & $111.17 \pm 18.21$ & $205.51 \pm 25.30$ & $14.78 \pm 3.02$ & $14.11 \pm 3.96$ & $28.36 \pm 5.01$ & $0.66 \pm 0.24$ \\
\hline Free media & $65.30 \pm 17.85$ & $110.71 \pm 16.80$ & $205.76 \pm 26.19$ & $14.51 \pm 3.45$ & $14.37 \pm 3.82$ & $29.27 \pm 3.26$ & $0.64 \pm 0.22$ \\
\hline CCl4+Nilotinib & $44.04 \pm 10.18$ & $83.97 \pm 14.78$ & $176.39 \pm 22.37$ & $23.85 \pm 5.08$ & $19.70 \pm 4.42$ & $20.14 \pm 5.66$ & $0.99 \pm 0.21$ \\
\hline $\begin{array}{l}\text { CCI4+stem } \\
\text { cells exosomes }\end{array}$ & $55.77 \pm 15.78$ & $96.480 \pm 28.41$ & $173.25 \pm 26.41$ & $21.32 \pm 3.37$ & $18.33 \pm 3.25$ & $20.04 \pm 2.85$ & $0.80 \pm 0.26$ \\
\hline $\begin{array}{l}\text { CCl4+stem } \\
\text { cells exosomes } \\
+ \text { Nilotinib }\end{array}$ & $34.88 \pm 5.19$ & $80.10 \pm 17.83$ & $148.02 \pm 14.02$ & $23.28 \pm 5.24$ & $22.80 \pm 3.82$ & $18.98 \pm 3.27$ & $1.02 \pm 0.21$ \\
\hline p-value & $<0.001 *$ & $<0.001 *$ & $<0.001 *$ & $<0.001 *$ & $<0.001 *$ & $<0.001 *$ & $<0.001^{*}$ \\
\hline
\end{tabular}

Table 2: Correlation between the oxidative stress markers and hydroxyproline content:

\begin{tabular}{|l|l|c|}
\hline & & $\begin{array}{c}\text { Hydroxyproline content } \\
\text { (ug/mg liver) }\end{array}$ \\
\hline \multirow{2}{*}{ MDA } & $\mathrm{r}$ & 0.272 \\
\cline { 2 - 3 } & $\mathrm{p}$ & $0.036^{*}$ \\
\hline \multirow{2}{*}{ GSH } & $\mathrm{r}$ & -0.528 \\
\cline { 2 - 3 } & $\mathrm{p}$ & $<0.001^{*}$ \\
\hline \multirow{2}{*}{ NOS } & $\mathrm{r}$ & 0.346 \\
\cline { 2 - 3 } & $\mathrm{p}$ & $0.007^{*}$ \\
\hline \multirow{2}{*}{ SOD } & $\mathrm{r}$ & 0.385 \\
\cline { 2 - 3 } & $\mathrm{p}$ & $0.002^{*}$ \\
\hline \multirow{2}{*}{ CAT } & $\mathrm{r}$ & -0.599 \\
\cline { 2 - 3 } & $\mathrm{p}$ & $<0.001^{*}$ \\
\hline & $\mathrm{r}$ & -0.463 \\
\cline { 2 - 3 } & $\mathrm{p}$ & $<0.001^{*}$ \\
\hline
\end{tabular}



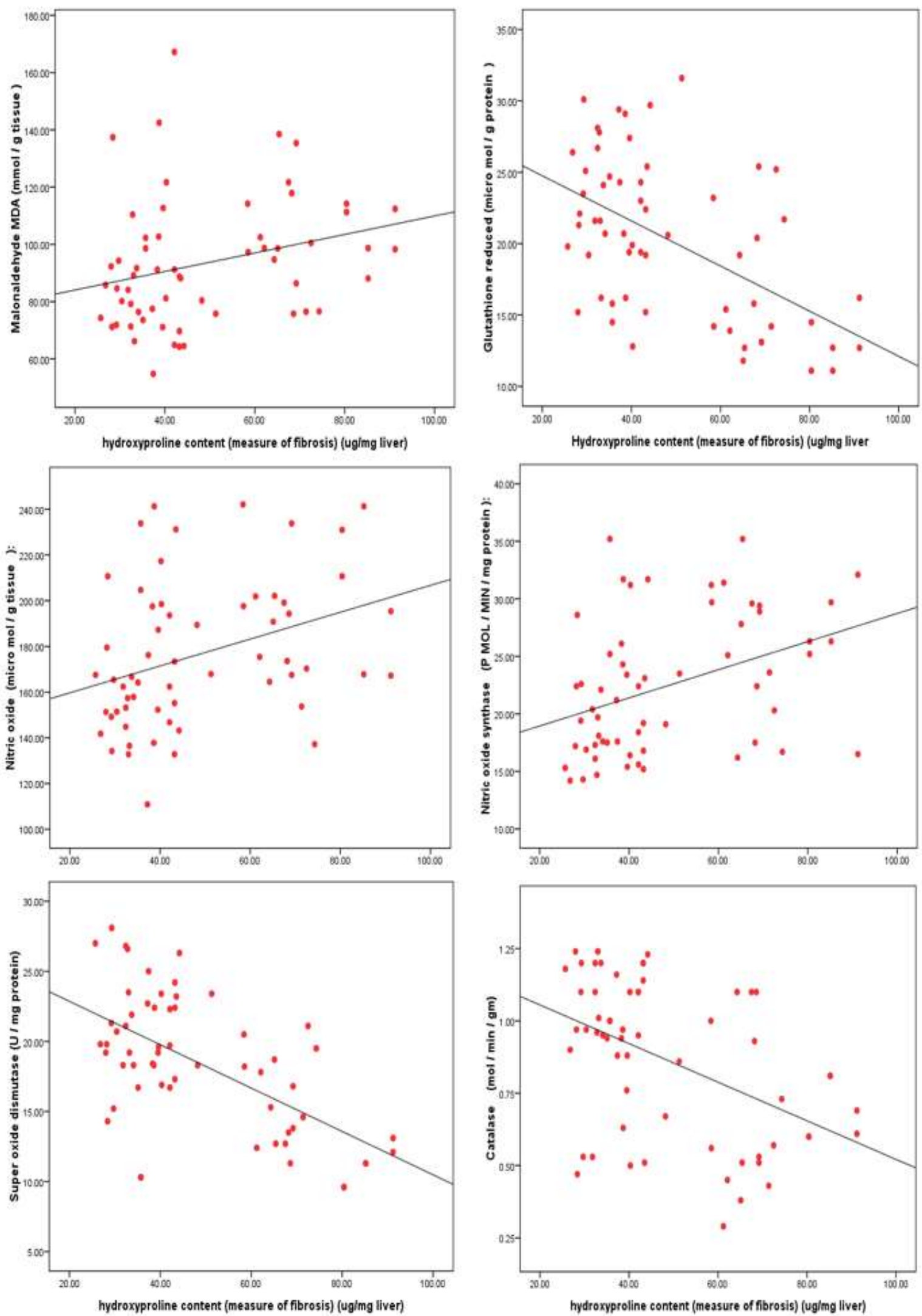

Figure (1): Corre lation between the oxidative stress markers and hydroxyproline content 